\title{
A Comparative Analysis of Mathematics Achievement Between Boys and Girls: The Case of Lower Cycle Secondary Schools Students of Addis Ababa
}

\author{
Yosef Hailu* Ayele Kumsa \\ College of Education and Behavioural study, Madda Walabu university, PO box 247 Bale-Robe, Ethiopia
}

\begin{abstract}
This study was designed to make a comparative analysis of mathematics achievement between girls and boys at lower secondary education level. It was also aimed at investigating the extent of association between girls' mathematics achievement and school type. Besides, students' attitude towards mathematics, parents' attitude and teachers' attitude on students' mathematics performance based on their gender were analyzed. To this end, the study has employed both quantitative and qualitative data gathering methods. Instruments were applied to 608 boys and 672 girls drawn from 10 schools (five schools each from government and non-government) on the basis of multistage sampling techniques. Independent sample t-test and chi-square analyses were employed. The results of data analyses revealed that mathematics achievement was strongly associated with students' gender and girls' achievement was significantly lower than that of boys. However, girls' mathematics achievement did not show a significant difference between government and non-government schools. Further, among students' attitude scores, girls' self-confidence on mathematics was significantly lower than that of boys. However, students' belief about the usefulness of the mathematics and their perception of the subject as a male domain didn't show a significant difference between boys and girls. Parents' and teachers' attitude on students' mathematics performance gender wise were showed a significant difference between boys and girls favoring boys. Moreover all these attitudinal scores were positively correlated with students' mathematics achievement score except for girls' perception of the subject as a male domain. The analysis of students' daily household working hours had shown a significant difference between boys and girls and it was found to be positively correlated with their achievement. It was evident that traditional stereotypes, which favour male dominance in mathematical ability, were still prevalent at modest level in the schools studied. Thus, a concerted effort by teachers, parents, relevant agencies, and the government is required to ameliorate the prevailing gender gap in mathematics achievement.
\end{abstract}

Keywords:, household working, attitude in mathematics performance gender wise DOI: $10.7176 / \mathrm{JEP} / 10-10-09$

Publication date: April $30^{\text {th }} 2019$

\section{Introduction}

Competence in mathematics has long been identified as a critical skill directly related to education and occupational choices. Yet, compared with men, fewer women choose advanced level of mathematics courses and enter mathematically oriented careers. As Rosser (1995) reported that by far, more girls than boys tend to quit secondary school mathematics prematurely. This had severely crippled their adult lives as mathematics is often considered as a gate-keeping course for controlling access to the most lucrative professions, such as science, engineering and others. In this regard as Morgade and Bonder (1995) described, it is common to observe in the world of work that many individuals, mainly women, are removed from recruitment for these professions due to their lack of ability and/or low performance in quantitative courses.

Different researchers have forwarded a variety of explanations for girls' underachievement in mathematics. Generally speaking, differences in achievements of girls and boys emanate from the interplay of personal, social, cultural, and institutional factors (FAWE, 1997; Genet, 1991; Keynes, 1989; Rosser, 1995; UNESCO, 1984). Differential expectations of parents, school teachers, peers and community as a whole in a given society are responsible for students' performance in quantitative subjects. As this favors boys it has a detrimental influence on girls' performance in mathematics. Further, research has also found that, more often than not, majority of girls do not show interest in learning mathematics as they think it is a masculine subject (Fox, 1981).

Due to cultural influence especially Ethiopian girls are expected to work more at home compared with boys. However learning mathematics requires a lot of time and energy as a student is required to do lots of exercises from time to time. Thus, if a student is excessively engaged in household chores and other responsibilities, she or he may perform badly specially in mathematics. Such attitudes and practices needs to check the extent of the situation in the contemporary local settings.

Generally, the problems of the study mainly aimed at comparing girls' mathematics achievement between the two school types (i.e. private vs. government) and compare girls' and boys' mathematics achievement at the 
lower cycle of secondary education (grade 10) in Addis Ababa city. To this end the study tried to examine the underlying factors particularly students' attitude [belief on the usefulness of mathematics, self-confidence on mathematics and perception of the subject as a male domain (hereinafter "usefulness", "self-confidence" and "male domain" respectively)], parents' and teachers' attitude for boys and girls mathematics performance and students' daily household working hours. Besides, the study further tries to see the proportion boys and girls on in the two academic choice, social and natural science, and whether these choices influenced by mathematics performance.

Thus, the study raised the following issues as a major problem;

(4) whether or not the average mathematics achievement of girls' significantly less than that of boys'.

$\stackrel{y}{\rightarrow}$ girls' attitude (usefulness and self-confidence) towards mathematics compared to boys'.

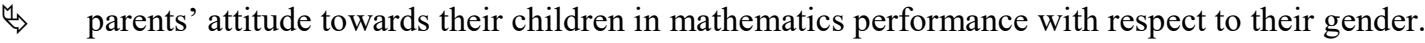

$\stackrel{4}{\rightarrow}$ teachers' attitude for boys' and girls' in their mathematics performance.

$\stackrel{4}{4}$ girls' daily household working hours compared with boys'. And its' relation with their achievement mathematics.

\section{METHOD OF THE STUDY}

\subsection{Design of the study}

The study utilized both quantitative and qualitative data which meant a mixed type. The quantitative part was a descriptive survey of both correlational and comparison type. After a detailed review of literatures, the study identified students' attitude (usefulness, self-confidence and male domain), parents' attitude, teachers' attitude and students' household working as dependent variable and mathematics achievement score as independent variables. The qualitative data were collected concerning about students' attitude and their academic choice and teachers' attitude.

\subsection{Sources of Data}

Primary data sources concerning about students' attitude, teachers' attitude, students' daily household working hours and students' academic choice for the study were grade 10 students and mathematics teachers whereas secondary data source for parents' attitude were again the same students in the lower cycle secondary schools in Addis Ababa. Data about number and distribution of students and schools were obtained from Education Bureau of Addis Ababa City Administration.

\subsection{Participant of the Study}

The study included mathematics teachers and grade 10 students of lower secondary schools of Addis Ababa city in the year 2008/09 which constitute a total population of 52,600; out of which 24,453 boys and 27,547 girls.

\subsection{Sampling Technique}

A multistage sampling procedure was employed to select the subjects of the study. In the first stage, the schools were stratified as governmental ( 34 schools) and nongovernmental (104 schools) that constitute a total number of 52,600 grade ten students. All in all 10 schools, 5 from each type of schools, were selected based on a stratified sampling procedure. Finally, 4 sections from each of the selected governmental schools and 4 sections from each nongovernmental school were again selected with a simple random sampling method. Based on the above sampling methods the total number of the sample size became 1333 students. Out of this total number of students only 53 students couldn't participate in the study and which made the response rate $95 \%$. In other words, a total of 1280 (boys 608 and girls 672) students were participated in the study.

Table1: Sample of the study by schools.

\begin{tabular}{|l|l|l|l|}
\hline School Name & No. of Sections Taken & No. of Students & Respondents in (\%) \\
\hline Addis Ketema & 4 & 133 & $10.4 \%$ \\
\hline Birhan Guzo & 4 & 131 & $10.1 \%$ \\
\hline Brace Youth Academy & 4 & 122 & $9.5 \%$ \\
\hline Dandi-Boru & 4 & 122 & $9.5 \%$ \\
\hline Derartu Tulu & 4 & 129 & $9.4 \%$ \\
\hline Ginbot Haya & 4 & 128 & $10 \%$ \\
\hline Menelik II & 4 & 133 & $10.4 \%$ \\
\hline Mizkaye-Hizunan & 4 & 126 & $9.8 \%$ \\
\hline School of Tomorrow & 4 & 121 & $10.3 \%$ \\
\hline Shimeles Habte & 4 & 135 & $10.6 \%$ \\
\hline Total & 40 & 1280 & $100 \%$ \\
\hline
\end{tabular}

In gathering the qualitative data, based on a snowball sampling method 5 mathematics teachers and 20 
students were participated for an interview.

\subsection{Instruments}

The major study variables were students' mathematics achievement, school types, students' attitude, parents' attitude, teachers' attitude, household working hours of students and their academic choices. Without changing the core meaning of Fennema-Sherman attitudinal scale, some modification was made while translating them into Amharic version in order to suit the local setting with the involvement of linguistic and curriculum professionals. This attitudinal scale includes students' belief about the usefulness of mathematics, students' selfconfidence on mathematics, students' perception of mathematics as a male domain, parents' and teachers' attitude for boys' and girls' mathematics performance. Questionnaire about household working hours of students was prepared based on the Ethiopian First and Second National Learning Assessment of Grade 4 and 8 Students respectively. Students' academic choice in the next educational level (grade 11 \& 12) has two options namely "social science" and "natural science" according to the Ethiopian education system for students who passed the lower secondary cycle successfully. Thus, these two preferences provided in order to collect data about students' academic choice. In gathering the qualitative data, structured and semi-structured interview were prepared to obtain data about students' attitudes, the relation between their academic choice and mathematics achievement and about teachers' attitude. In order to collect these data mathematics achievement test, questionnaires, interview and document analysis were employed.

\section{Mathematics Achievement Test}

An objective type of mathematics test was constructed in order to investigate whether there has been

$\Leftrightarrow$ a significant mean difference in mathematics achievement between boys and girls.

$\stackrel{\leftrightarrow}{\rightarrow}$ a relation with students' attitude, parents' attitude, teachers' attitude and students' daily household working hours.

By looking the annual plan of sample schools, the test included the major content areas which were already covered at the time of data collection.

\section{Questionnaires}

The Fennema-Sherman attitudinal scale were designed on a five point Likert-type scale with values as $1=$ "strongly agree", 2 = "agree", $\quad 3=$ "neutral", 4 = "disagree" and 5 = "strongly disagree". Each of them containing 12 questions and of which, half of them (6 questions) reflected a positive attitude and the remaining ones a negative attitude (Appendix I: Part II).

In order to assess the relationship between the daily hours of household working and their mathematics achievement (Appendix I: Part III), a question was presented to the students to select their average daily household working hours in the following form:

$$
\begin{aligned}
& 1=\text { less than } 3 \text { hours } \quad 2=\text { between } 3 \text { and } 5 \text { hours } \\
& 3=\text { between } 5 \text { and } 7 \text { hours } \quad 4=\text { more than } 7 \text { hours. }
\end{aligned}
$$

Finally, to identify the proportion between girls and boys academic choice a question was prepared having choices of "natural science" and "social science" (Appendix I: Part IV).

\section{Interview}

Structured and semi-structured interview were made for 20 mathematics teachers and 5 students in order to get additional qualitative data about the attributes which affects girls' mathematics achievement and the relationship between academic choice and their mathematics performance.

\section{Document Analysis}

In order to select the required number of schools with their type (government and non-government) for the study, all lists of schools were taken from Educational Bureau of Addis Ababa City Administration..

\subsection{Validity and Reliability}

In order to construct a valid achievement test different professionals in the area were involved and around one third of the questions were taken from national examination papers which have been believed to be a standard type in the country. After translating the Fennema- Sherman attitudinal measuring scales into Amharic version (Appendix II) a pilot test was conducted and finally making their reliability to be high (alpha $=0.71$ to 0.79 ). In the qualitative data, to verify the convergence and divergence of respondents' view triangulation technique were used. A peer debriefing was also made on the collected information with the researcher's colleagues who were engaged in the teaching profession in order to keep the trust worthiness of the study.

\subsection{Procedures}

Preparation of the achievement test passed the following procedures:

- Three experts were recruited to prepare the achievement test based on their qualification, experience and ability to prepare a valid test in the grade level.

- The selected experts were provided one day training on important issues by experts from the National 
Organization for Examination (NOE). On the principles and techniques of test construction and Blooms' taxonomy of cognitive domain.

- Following the training at least 50 items were developed and revised by senior experts at NOE in order to insure whether the requirements of test construction were adequately met.

- A pilot test was held at two schools, each from the school types, so as to identify the right items depending on item analysis. Finally 40 items were chosen to constitute the final version of mathematics achievement test.

- The final version of the test was administered towards the end of the first semester of the academic year. This time was chosen because it was believed to minimize the probability of achievement differences due to differences in students' preparations. It was believed that all students had made sufficient preparations for their first semester examination at the time of test administration. Furthermore, extra care was taken to avoid information leakage about the achievement test up until the administration of the test. In short, every effort was made to control the effects of extraneous variables and to ensure the quality of the test. And finally, each individual's score out of 40 was converted into $100 \%$.

The interview with students as well as teachers was conducted with informed consent of the participants. Each of the participants was informed on the purpose of the study in order to get their willingness to be involved in the study and also they were informed that the information obtained will be kept confidential. While taking the achievement test and filing all the questionnaires students were told not to write their name rather the researcher used a code to identify each student's test paper and the corresponding questionnaires.

\subsection{Data Analysis}

Before analyzing the collected data from the selected schools, effective data entry tasks were done using Microsoft Excel application software. Following data entry, an intensive data cleaning, and editing, checking and re-checking activities were performed. Following the data management process, the data analysis task was performed with the help of SPSS (Statistical Package for Social Science) version16. This is to produce:

- mean, standard deviation and percentage of basic information and distribution of scores. This helped for an easy understanding of the level of mathematics achievement by gender. Further, the attitude of parents and teachers toward student's mathematics performance gender wise, usefulness, confidence and male domain, students' household engagement and their academic choice were described in terms of mean, standard deviation and percentages where they were necessary.

- a two tailed an independent-sample t-test at $\mathrm{p}=0.05$ was conducted to see whether or not the observed mean scores difference:

$\checkmark$ of mathematics achievement between boys and girls was significant.

$\checkmark$ between the attitudinal scores and students' mathematics achievement was significant for both boys and girls independently.

- a Pearson correlation analyses were used to see the relation ship between self-confidence, usefulness, male domain, parents' attitude, teachers' attitude and students' daily hours of household engagement with their mathematical achievement.

- a Chi-square analysis was employed to see whether there was a significant difference between boys and girls in their daily spending hours in domestic chores.

- a descriptive data that provides percentage distribution of students' academic choice up on their next educational level were also employed.

The data gathered through interview from students and subject teachers concerning about students' attitude and mathematics performance, teachers' attitude and students' academic choice were carefully transcribed, coded, categorized based on similar attributes.

\subsection{Summary and Conclusion}

The main purpose of this study was to investigate the factors causing gender disparity in mathematics performance among lower secondary school students of Addis Ababa and bring about prevailing traditional gender stereotypes into perspective. To achieve this broad objective, the study involved 1280 grade ten students (608 boys and 672 girls) drawn from 10 schools ( 5 government and 5 non-government) on the basis of multistage sampling technique. The study had employed both quantitative and qualitative methods. The data collection instruments were mathematics achievement test, questionnaires, interview and document analysis. The quantitative data were analyzed with the help of SPSS software by means of which relevant statistics have been produced.

The results of the analyses indicated that, among other things, there was a significant mean difference between boys (59.24) and girls (48.29) in mathematics achievement. Thus, a gender gap of 10.5 percent mean difference was found to be large enough to conclude that girls had performed significantly lower than boys in 
Grade 10 mathematics test in Addis Ababa (t1280 $=-14.65, \mathrm{p}<.005)$.

When girls' mathematics performance was analyzed in terms of school type there was no significant difference between the average scores of girls in government (53.00) and non-government (52.80) schools $(\mathrm{t} 672=0.24, \mathrm{p}>0.05)$. Thus, it is possible to say school type neither governmental nor nongovernmental don't have an influence on girl' mathematics achievement.

When students' self-confidence in relation with mathematics performance analyzed, a significant difference were probed between boys (47.79) and girls (37.24) favoring boys (t1280=-24.57, $\mathrm{p}<0.05$ ). The result indicated that most girls appeared to believe mathematics is hard subject for them and feel they are not good at the subject. However, among these girls who have a relative better self confidence on the subject looked to score a better result in the achievement exam.

While analyzing students' believe on the usefulness of mathematics in their future career, the result didn't revealed a significant difference between boys (46.74) and girls (46.38) $(\mathrm{t} 1280=-.937, \mathrm{p}>0.05)$. This result leads to conclude that girls have an equal awareness as boys on the importance of the subject on their academic choice and consequently on the future job market. But still among girls who had more awareness about the use of the subject could score a higher result on the achievement exam.

Students' perception of the subject as male domain didn't show a significant difference between the two genders $(\mathrm{t} 1280=-.65, \mathrm{p}>0.05)$. This result indicated that girls almost equally as boys feel mathematics as a masculine subject. However looking at the mean result boys (48.21) perceive the subject as a male domain more than girls (41.05) do. Further analysis among the girls revealed those who felt they could perform equally as boys achieve relatively a better score on the exam compared to the remaining girls who felt the opposite.

Parental attitude on mathematics performance gender wise shown a significant difference between boys and girls favoring boys $(\mathrm{t} 1280=-22.24, \mathrm{p}<0.05)$. But among girls whose parents have an attitude that girls could perform mathematics equally as boys score high in the achievement exam compared to having parents who feel the opposite. From the result it can be concluded that parents' still perceive girls as incapable of performing mathematics as boys do and their perception on mathematics performance of girls could bring a positive result on their daughter's success on the subject.

Teachers' attitude on mathematics performance students gender wise had shown a significant difference between boys and girls favoring boys ( $\mathrm{t} 1280=-38.70, \mathrm{p}<0.05)$. However, those girls who were treated equally as boys and perceived capable of performing mathematics as boys by their teachers score a better result in the test compared to the remaining girls. Based on the result it is possible to conclude that most teachers don't equally view and treat girls as boys in respect to mathematics performance. Moreover this biased attitude of teachers towards their students contributes for the underachievement of girls.

Based on the analysis from students' engagement on the daily hours of household work, out of the total $10 \%$ (128) students who spent maximum hours (i.e. more than 7 hours) girls constitute the largest portion which was $7.5 \%$ (96) and boys accounted only $2.5 \%$ (32). While from students who spend the least hours (i.e. less than 3 hours) only $7.5 \%$ (128) were girls and the majority $25 \%$ (320) were boys out of the total $32 \%(416)$ of students. This result had shown a significant difference between the two gender type favoring boys $(\chi 2=248.06$, $\mathrm{p}<0.05$ ). In addition, as the number of daily working hours at home increases students' achievement result decreases. It can be concluded that girls spend more hours in domestic chores than boys do and those girls who didn't spend lots of hours at domestic chores score a better result in the achievement test compared with those girls who spend more hours.

From students' academic choice up on their next educational level, only few girls $(10.00 \%)$ prefer to study natural science compared to boys $(29.68 \%)$; however, most girls $(42.50 \%)$ prefer to study social science compared to boys $(17.82 \%)$. Girls put as a reason for their low portion in the choice of natural science stream was their current low performance in mathematics couldn't make them competent in their future higher educational levels so they tend to prefer social science field in order to avoid the involvement of mathematics. Thus, this result leads to say the lower participation of girls in natural science fields is due their stumpy performance in mathematics.

In summarizing the research findings, educators have to try to make mathematics, equitable, and exciting to all students. Parents need to encourage every child's achievement in mathematics irrespective of gender bias; and should give girls ample time to study specially mathematics. Teachers should give girls equal chance as boys in mathematics classes and encourage them to solve mathematical problems independently and in collaboration with school administrators, teachers should facilitate in praising their progress in different types of rewards. Such things will help female students to develop a self confidence on the subject and perceive the subject as independent of one's gender. To close the gender gap, though, schools and parents will have to continue their efforts.

\subsection{Recommendations}

In a country where social and educational research has not been well established, a study of this sort will have a 
far-reaching implication in both theory building exercise and addressing performance inequity problem by gender. Little has been known about factors associated with girls' mathematics performance and the reasons underlying such differences specially focusing attitudes in the Ethiopian education system in general and in Addis Ababa City Administration in particular.

One course of action might involve helping students overcome their own self-defeating attitudes or lack of self confidence. As this review has advocated, feelings of competence are psychological events, depending far more on the subjective meaning given to achievement experience than on actual levels of attainment. In that regard, adults should function primarily as interpreters of reality. It is critical then that teachers and parents become more sensitive to their own attitudes towards mathematics and perpetuating stereotypic views of mathematics achievement or careers in the quantitative fields as inappropriate for girls.

In addition, steps should be taken by school counselors in promoting girls' to develop a self confidence with appropriate procedure so that they could have a better participation in mathematics and mathematics related science fields. Rewarding those girls who achieve a better score in mathematics will help others to develop a feeling that mathematics is not merely a masculine subject or natural acquired for being a male. In this regard schools could practice such an activity in collaboration with different organizations (governmental or nongovernmental) that are working on this area. Schools should arrange a program for girls to visit places that enabling them to appreciate science and technology innovations so that it helps them to look mathematics through that.

The study further suggests that parents should let their daughters to have a daily ample study time in order to make them a better achiever in mathematics. Moreover, in order to compensate hours of girls'

In addition, this study has highlighted important findings that can serve as key indicators for practical measures taken by the concerned authorities. Thus, the results of this study are expected to provide the necessary basis for policy makers, planners, teachers and school administrators to realize the magnitude of the problem and design viable and effective community based intervention measures for mitigating the problem under consideration.

As cultural differences were not directly addressed in this current study, future research should focus on this aspect as a possible interaction with gender on influencing mathematics performance. The current study only examined a limited number of schools. It would be interesting to be able to expand this study to look at several schools across different regions in order to draw upon a much larger data base.

Finally, the findings of this study may generate interest or assist as a stepping-stone for those who have the intention for further study in the field.

\section{Reference:}

FAWE, (1997). Female Education in Mathematics and Science in Africa, Unpublished Research Report, Nairobi. Fennema, E \& J. Sherman, (1977). Sex-related differences in mathematics achievement, spatial visualization, and affective factors. American Educational Research Journal, 14, 51-71.

Fox, L.H., (1981). The Problem of Women and Mathematics, New York: Ford Foundation.

Genet Zewdie, (1991). Women in Primary and Secondary Education, Gender Issues in Ethiopia, Addis Ababa: IES.

Keynes, H.B.(1989). Recruiting Girls for a More Successful Equation, Project report, University of Minnesota Institute of Technology.

Morgade, G., \& G. Bonder (1995). Women, Mathematics and Natural Science. The Scientific Education of Girls: Education beyond Reproach? Paris: UNESCO.

Rosser S.V. (1995). U.S. Women in Science and Feminist Theories, in R. Clair (ed.). The Scientific Education of Girls: Education beyond Reproach? Paris: UNESCO.

UNESCO, (1984). Wastage in Primary Education 1970-1980, Paris 